\title{
Reducing the Risk of Abandonment of Assistive Technologies for People with Autism
}

\author{
Peter Francis ${ }^{1}$, Lucy Firth ${ }^{1}$, and David Mellor ${ }^{2}$ \\ ${ }^{1}$ Department of Information Systems, The University of Melbourne, Australia \\ psfran@pgrad.unimelb. edu.au \\ ${ }^{2}$ Department of Psychology, Deakin University, Australia
}

\begin{abstract}
This paper reports on an investigation that found that conventional techniques for including users in technology design are likely to fail if the user has autism. The heterogeneity of autistic symptomatology across cognitive, social, behavioural and communication domains suggests a 'single user' environment, while rendering typical design interaction techniques meaningless, making the need for assistive technologies great, and the risk of abandonment high. This complex problem of urgency and constraint was addressed through a Delphi study with a panel of psychologists critiquing design activities for people with autism. The major finding is that while each of the activities may work if modified, all require that the designer is well acquainted with autism in general and has a close working relationship based on trust with the individual user. If these requirements are met, there is no reason that the abandonment rate cannot be reduced.
\end{abstract}

\section{Introduction}

There is a demonstrated need by people with cognitive disorders for visual tools [1]. These tools provide assistance with organisation, memory and other activities and, as such, contribute greatly to the independence of the user. Such tools, however, are often paper-based and bulky so, while functional, they are likely to present social problems for the self-aware user.

With the increasing availability of suitable handheld platforms, such as personal digital assistants (PDAs) and mobile phones, there is great potential to offer more discrete and socially acceptable versions of existing visual supports, in addition to supporting the user in ways previously not possible.

User acceptance, however, is not assured. It has been reported [2] that one-third of all assistive devices are abandoned (citing a range of $8 \%$ for life-saving devices to $75 \%$ for hearing aids). That research also noted that user involvement in selection and design is a key factor in adoption. Importantly, co-design activities should go beyond functionality into preferences as devices "must be aesthetically pleasing, age appropriate, fashionable, and culturally and socially acceptable. Devices that look 'handicapped' are not adopted" ([2] p.6). The additional associated tendency of people with autism toward rigidity and resistance to change strongly suggests that 
user-centered and participatory approaches be adopted in the design of assistive digital technologies for this group if high rates of abandonment are to be avoided.

\subsection{The Problem with Direct Involvement}

Autism presents traits that should be considered before working directly with this group. Here those traits are discussed in terms of their potential to cause failure to achieve a technology that will be adopted and not abandoned by the user, and (more importantly) cause harm to those participating in the design process.

Harm to the participant:

- Management of expectations can be a consideration with any design process that directly involves users [3]. Given that people with autism have a greater potential for misunderstandings, coupled with the difficulties of dispelling misconceptions [4], additional care must be taken in allowing expectations to be developed. Additionally, many design processes involve a degree of learning by the usersubject (e.g. prototyping), this can be disconcerting, even distressing for this group if at the end of the design 'experiment' the prototype is then withdrawn and the newly acquired skills no longer have an outlet.

- As the onset of depression among the target group has been attributed in part to 'negative life events' [5] care should be taken that the experience of participation in research and design activities be a positive one, importantly from the viewpoint and perception of the target user, not from the researcher's perception. Reports of suicidal tendencies [6] would indicate that care should be taken not to exacerbate such negative emotions by using techniques and procedures that have not been first the subject of careful examination.

Design failure:

- Poor imaginative, communication and cognitive skills [7] may render the design interaction too difficult for the user-subject.

- Fear of failure [4] and motivational difficulties may make it difficult to engage people with autism in the design process.

- Interpretation of the level of understanding or emotional state of the user can be difficult. For example, laughter or giggling may reveal that the person is anxious or stressed [4]. This may be misinterpreted by the untrained designer.

- Variability of traits in the group means that the designer is unable to make assumptions about the abilities of the subject-user's abilities.

Therefore, an empirical study was designed to find ways to overcome these problems in engaging people with autism in the design of assistive digital technologies specifically for their needs.

\section{Method}

Given the above traits it was deemed appropriate to design a method for this exploratory study that did not directly involve people with autism. Moreover, due to the stress on families coping with autism and the fact that they, and carers, typically 
have experience of only one person with autism it was decided to design a method around a third expert group - psychologists. The Delphi Method was considered appropriate for data collection as it enabled the time for panelists to consider and reflect upon the application of unfamiliar processes to a domain that they were considered expert in. The experts in this study were each given outlines of design techniques placed in the context scenario of a youth with autism transitioning from school to work, and asked to comment on the suitability of those design techniques given the traits of autism. The panelists did not know who the other Delphi panelists were, and only communicated to the researcher, not to one another. The material thus gained, were analysed, a summary produced including dissenting comments, and used as the basis for questions for the next Delphi round. The Delphi study ran for three rounds. The involvement of 7 panelists is consistent with recommendations [8].

Data collection was mainly in the form of written responses to mostly open questions, therefore qualitative techniques such as identification of themes and clustering of issues were used in the analysis. In order to facilitate the involvement of expert panelists who were dispersed geographically, and were busy, an online Delphi Method was developed using a commercial online survey tool (QEDML).

Four scenarios were developed to describe the use of four techniques by a technology designer at the requirements stage of a user-centered design project. The choice of techniques was based upon offering a variety of different levels of userdesigner interaction. They also required a variety of different skills of the user, and were situated in a range of locations from laboratory to field. In addition to being techniques used in technology design, the essential elements of all four activities had some precedence for use with people with autism (see for example, [4] and [9]). The four techniques were:

- a designer and video-recordist follows the subject-user throughout the day for latter discussion with the subject-user (field location; low level of user participation and control)

- the subject-user thinks aloud while the designer listens for later discussion with the designer (field location; moderate level of user participation and control)

- the subject-user self photographs throughout the day for later discussion with a designer (field location; high level of user participation and control)

- the subject-user role-plays (using models in a doll's house setting) while the designer watches (laboratory location; high level of user participation and control)

The Delphi panelists were asked to comment on the likely impact of the techniques on the subject-user, and on the potential for the process to produce usable, credible and meaningful data for the designer.

Although most of the questions put to the panelists were scenario-specific (e.g. how well would the subject-user cope with the need to role play in the doll's house) the majority of the responses were general. Therefore, the draft guidelines developed are general in flavour, and require the designer to become well acquainted with the subject-user's unique individual condition and abilities. This is consistent with findings in a study investigated appropriate educational practices for students with autism that, as the target group is heterogeneous in nature, no single practice would be likely to suit all students [10]. 


\section{Discussion and Conclusion}

It is possible to include users with autism directly in the design process, but:

- Care must be taken to conduct a thorough assessment of the user and their abilities, motivators and behaviours prior to commencement of the design process, no matter which technique is adopted.

- Development of a solid and trusting working relationship is paramount when working with this user group.

- The designer should be experienced in the disorder. This is especially relevant as interpretation of the user's emotions and level of understanding may be difficult.

- Each of the four techniques that were investigated would appear to work with some of the target group if the techniques are modified in accordance with the individual's condition. This conclusion is dependent, of course, on the three preceding conclusions: thorough assessment and planning by a designer experienced with the target group and with the user.

The literature and our study suggest no reason why the likely high rate of abandonment of assistive technologies by users with autism cannot be significantly reduced by appropriate inclusion of users in the design process.

\section{References}

1. Hodgdon, L.: Visual Strategies for Improving Communication: Practical Supports for School \& Home. Quirkroberts Pub.; Michigan (1996)

2. Kintsch, A., and dePaula, R.: A Framework for the Adoption of Assistive Technology. SWAAAC 2002: Supporting Learning Through Assistive Technology, Winter Park, CO, USA. [http://www.cs.colorado.edu/ 13d/clever/assets/pdf/ak-SWAAAC02.pdf] (2002)

3. Preece, J., Rogers, Y. and Sharp, H.: Interaction design: beyond human-computer interaction. John Wiley \& Sons.: New York (2002)

4. Attwood, T.: Asperger's Syndrome: A guide for parents and professionals. Jessica Kingsley Publishers.; London (1998)

5. Ghaziuddin,M. Ghaziuddin, N. and Greden, J.: Depression in persons with autism: implications for research and clinical care. Journal of Autism and Developmental Disorders, Aug; 32(4):299-306 (2002)

6. Barnhill, G.: Social attributions and depression in adolescents with Asperger syndrome. Focus on Autism and Other Developmental Disabilities; Spring; 16, 1; 46-53 (2001)

7. Griswold, D. E., Barnhill, G. P., Myles, B. S., Hagiwara, T. and Simpson, R. L.: Asperger syndrome and academic achievement. Focus on Autism and Other Developmental Disabilities, Summer, 17, 2, 94-102 (2002)

8. Delbecq, A. L., Van den Ven, A. H. and Gustafson, D. H.: Group techniques for program planning: a guide to nominal group and Delphi processes. Scott, Foresman.; Glenview, Ill. (1975)

9. Danielsson, H. and Svensk, A.: Digital Pictures as Cognitive Assistance. AAATE 2001, September 3-6, Ljubljana, Slovenia. [http://www.english.certec.lth.se/isaac/] (2001)

10. Iovannone, R., Dunlap, G., Huber, H. and Kincaid, D.: Effective educational practices for students with autism spectrum disorders. Focus on Autism and Other Developmental Disabilities, Fall, Vol.18, No.3, 150-165 (2003) 